\title{
CONDENAÇÕES DE BOVÍDEOS ABATIDOS SOB INSPEÇÃO MUNICIPAL EM SANTARÉM - PA
}

\author{
Maressa Fideles Pereira'; Luís Gabriel Alves Cirne²; Kedson Alessandri Lobo Neves²; Gustavo da Silva \\ Claudiano ${ }^{2}$; Andressa Santana Costa ${ }^{1}$; Eloinny Karina Figueira Castro'; Adriana Caroprezo Morini²; \\ Gleidson Giordano Pinto de Carvalho ${ }^{3}$
}

1Discente de Zootecnia, Instituto de Biodiversidade e Florestas (IBEF), Universidade Federal do Oeste do Pará (UFOPA), Santarém, Pará, Brasil, fidelispereira19@hotmail.com, kika.andressa@gmail.com, eloinnykarina@gmail.com

2Docente e pesquisador (a), IBEF, UFOPA, Santarém, Pará, Brasil, Igabrielcirne@hotmail.com, kedson_neves@hotmail.com, claudianovet@yahoo.com.br,drimorini@gmail.com

${ }^{3}$ Docente e pesquisador, Universidade Federal da Bahia (UFBA), Departamento de Zootecnia, Salvador, Bahia, Brasil, gleidsongiordano@yahoo.com.br

RESUMO: O estudo objetivou apresentar ocorrências de condenações de bovídeos abatidos sob serviço de inspeção municipal em Santarém - PA. Para coleta dos dados, foram consultados relatórios mensais de abate de três abatedouros municipais, fornecidos pela Secretaria Municipal de Agricultura e Pesca (SEMAP). No período avaliado, correspondente de janeiro a dezembro do ano de 2016, foram abatidos 52.046 bovídeos, dos quais 49.486 eram bovinos e 2.560 bubalinos, com total de 296 condenações, em sua maioria, procedentes do município de Santarém com 127 carcaças condenadas. As causas foram: lesões sugestivas de tuberculose (72,30\%) e brucelose (24,66\%), hematomas generalizados (1,35\%), Caquexia (1,01\%), Peritonite $(0,34 \%)$ e morte no curral (0,34\%). Das 296 ocorrências, os índices de condenações em machos e fêmeas, responderam por 16,22\% e 83,78\%, respectivamente. O município de Santarém apresentou maior incidência em condenações, na qual a espécie bovina predominou, com destaque para as fêmeas que apresentaram, principalmente, lesões sugestivas de tuberculose e brucelose, além de hematomas.

PALAVRAS-CHAVE: Abate, Doenças ocupacionais, Patologia.

\section{CONDEMNATIONS OF BOVIDAE SLAUGHTERED UNDER MUNICIPAL INSPECTION IN SANTARÉM - PA}

ABSTRACT: the present study aimed to present occurrences of condemnations of bovidae
slaughtered under municipal inspection service in Santarém - PA. For data collection,
monthly slaughter reports from three municipal slaughterhouses, provided by the
Municipal Department of Agriculture and Fisheries (SEMAP), were consulted. In the period 
analyzed, from january to december of the year 2016, 52.046 bovines were slaughtered, of which 49.486 were bovine and 2.560 buffalo, with a total of 296 convictions, mostly from the municipality of Santarém with 127 condemned carcasses. The causes were: lesions suggestive of tuberculosis (72,30\%) and brucellosis (24,66\%), generalized bruising $(1,35 \%)$, cachexia $(1,01 \%)$, peritonitis $(0,34 \%)$ corral $(0,34 \%)$. Of the 296 occurrences, the conviction rates in males and females accounted for $16,22 \%$ and $83,78 \%$, respectively. The municipality of Santarém had a higher incidence in condemnations, in which the bovine species predominated, especially females that presented, mainly, lesions suggestive of tuberculosis and brucellosis, in addition to hematomas.

KEYWORDS: Occupational diseases, Pathology, Slaughter.

\section{CONDENAS DE BÓVIDOS SACRIFICADOS MEDIANTE INSPECCIÓN MUNICIPAL EN SANTARÉM-PA}

RESUMEN: el presente estudio tuvo como objetivo presentar las ocurrencias de condenas de bóvidos sacrificados bajo el servicio de inspección municipal en Santarém - PA. Para la recolección de datos, se consultaron los informes mensuales de matanza de tres mataderos municipales, provistos por el Departamento Municipal de Agricultura y Pesca (SEMAP). En el período analizado, de enero a diciembre del año 2016, se sacrificaron 52.046 bovinos, de los cuales 49.486 fueron bovinos y 2.560 búfalos, con un total de 296 condenas, la mayoría del municipio de Santarém con 127 cadáveres decomisados. Las causas fueron: lesiones sugestivas de tuberculosis (72,30\%) y brucelosis (24,66\%), hematomas generalizados (1,35\%), caquexia (1,01\%), peritonitis (0,34\%) corral $(0,34 \%)$. De las 296 ocurrencias, las tasas de condenas en hombres y mujeres representaron 16,22\% y $83,78 \%$, respectivamente. El municipio de Santarém tuvo una mayor incidencia en las condenas, en el que predominaron las especies bovinas, especialmente las hembras que presentaron, principalmente, lesiones sugestivas de tuberculosis y brucelosis, además de hematomas.

PALABRAS CLAVE: Enfermedades ocupacionales, Matanza, Patología.

\section{INTRODUÇÃO}

A demanda por produtos cárneos tem aumentado gradativamente devido à elevação populacional e com a ascensão progressiva da renda per capita de países emergentes como o Brasil, China, Índia e 
Rússia. O Brasil sendo um país de clima tropical e de vasta extensão territorial, em torno de 8,5 milhões de km2, possui potencial para atender essa demanda, principalmente em função da produção bovídea proceder de sistemas produtivos que utilizam recursos nutricionais de baixo custo relativo (HOFFMANN et al., 2014).

Apesar do destaque na produção, alguns segmentos da cadeia ainda necessitam de melhorias a fim de garantir a qualidade do produto final. Sendo assim, uma produção de melhor qualidade possibilita, tanto para produtores como para frigoríficos, a redução de perdas, maior retorno financeiro para o setor, além da oferta de alimentos isentos de contaminantes (SILVA et al., 2016).

A questão sanitária é um fator fundamental para o âmbito comercial dos produtos de origem animal, e a cada ano o Brasil vem apresentando melhora no perfil sanitário dos rebanhos (OLIVEIRA， 2006; BRANDÃO， 2007).
Mesmo com a implantação de programas de controle de qualidade, as condenações de carcaças devido problemas ocorridos no manejo préabate ou no abate são ainda as principais causas de perdas econômicas (REZENDE LAGO et al., 2011). Consequentemente, o manejo inadequado no frigorífico resulta em carcaças com hematomas e inúmeros outros relacionados a falhas tecnológicas, sendo detectadas pelo serviço de inspeção (MACHADO et al., 2016).

Além disso, os prejuízos econômicos causados por doenças em ruminantes, ainda são alarmantes, com destaque para a brucelose e a tuberculose, consideradas as zoonoses mais comuns (ARAÚJO, 2009). De forma geral, apesar de apresentarem algumas peculiaridades quanto à sanidade, bovinos e bubalinos podem ser afetados pelas mesmas enfermidades (MACHADO et al., 2016).

$\mathrm{O}$ conhecimento de patologias que acometem bovídeos e que causam prejuízos econômicos é de grande 
importância para detectar pontos fracos passíveis de melhora na cadeia produtiva (CHAGAS et al., 2013). Porém, ainda há deficiência de pesquisas que visam informar a sociedade sobre o risco de certas enfermidades sobre à saúde pública. Assim, o presente estudo objetivou apresentar as causas de condenaç̧̃̃es registradas em carcaças de bovinos e bubalinos abatidos sob regime de inspeção municipal em Santarém no ano de 2016.

\section{MATERIAL E MÉTODOS}

O estudo foi conduzido no município de Santarém - PA, a partir de registros dos relatórios mensais de abate de três abatedouros (A, B e C) com Serviço de Inspeção Municipal (SIM) $\quad(n=3)$, fornecidos pela Secretaria Municipal de Agricultura e Pesca (SEMAP), os quais atuam no abate, processamento e expedição de carnes dentro dos limites do município.

Os relatórios constam de 12 meses de atividade referentes ao ano de 2016 dos frigoríficos $A$ e $B$, e 10 meses do frigorífico $C$, pois os meses de maio e dezembro desse último não foram localizados no setor responsável pelo fornecimento dos dados. As informações contidas nesses documentos referem-se, principalmente, sobre quantitativo de bovinos e bubalinos abatidos (machos e fêmeas) e de condenações totais.

Com base nesses dados foram calculados, a saber: o percentual de animais condenados em relação ao número de bovídeos abatidos de acordo com a procedência; o percentual de cada causa de condenação total em relação ao total de condenações; e o percentual de condenações nas espécies estudadas por classe sexual.

Após coleta e tabulação dos dados, esses foram organizados em planilhas do programa Excel e submetidos a análises descritivas na forma tabelas e gráficos.

\section{RESULTADOS E DISCUSSÃO}

Com exceção dos dados de maio e dezembro do abatedouro C, foram 
abatidos 52.046 bovídeos ( $n=49.486 \quad n=70$ bubalinos) condenações totais de bovinos; $n=2.560$ bubalinos), dos quais bovídeos procedentes de 14 municípios 17.811 eram machos e 34.235 fêmeas, da região de Santarém (Tabela 1). sendo detectadas 296 ( $n=226$ bovinos;

Tabela 1. Estimativa do total de animais condenados pelo município de origem.

\begin{tabular}{cccc}
\hline Município & Animais abatidos & Animais condenados & $(\%)$ \\
\hline Santarém & 2450 & 127 & 5,18 \\
Prainha & 2498 & 28 & 1,12 \\
Monte Alegre & 3691 & 27 & 0,73 \\
Alenquer & 2049 & 24 & 1,17 \\
Placas & 5991 & 22 & 0,36 \\
Uruará & 8463 & 16 & 0,18 \\
Rurópolis & 3417 & 14 & 0,4 \\
Mojuí dos Campos & 825 & 14 & 1,7 \\
Belterra & 2295 & 8 & 0,34 \\
Óbidos & 863 & 8 & 0,92 \\
Curuá & 736 & 3 & 0,4 \\
Itaituba & 1236 & 2 & 0,16 \\
Trairão & 48 & 2 & 4,16 \\
Juruti & 21 & 1 & 4,76 \\
\hline Total & 34583 & 296 & 21,58 \\
\hline
\end{tabular}

Fonte: SEMAP (2016), elaborado pelo autor.

Santos et al. (2007) afirmam que o município de Santarém não é grande produtor de carne e tem sua demanda suprida por Uruará (cerca de 80\%), Rurópolis, Placas e Monte Alegre, fato este comprovado no presente estudo.

Quanto ao percentual de carcaças condenadas, percebe-se que Santarém se encontra em posição de destaque com 5,18\%, quando comparada aos municípios de Monte Alegre (0,73\%), Placas (0,36\%), Uruará (0,18\%) e Rurópolis $(0,4 \%)$, os quais enviaram números significativos de animais para abate.

As 296 carcaças condenadas pelo serviço de inspeção municipal apresentaram, em sua maioria, três 
principais ocorrências: lesões sugestivas de tuberculose $(n=214 ; 72,30 \%)$ e brucelose $(n=73 ; 24,66 \%)$ além de hematomas generalizados $(n=4 ; 1,35 \%)$, totalizando $98,31 \%$ das ocorrências. A somatória das demais correspondeu $1,69 \%$, sendo: caquexia ( $n=3 ; 1,01 \%)$; peritonite ( $n=1 ; 0,34 \%)$ e óbito no curral $(n=1 ; 0,34 \%)$ (Figura 1).

Figura 1. Ocorrências registradas pelo serviço de inspeção municipal de Santarém, no ano de 2016.

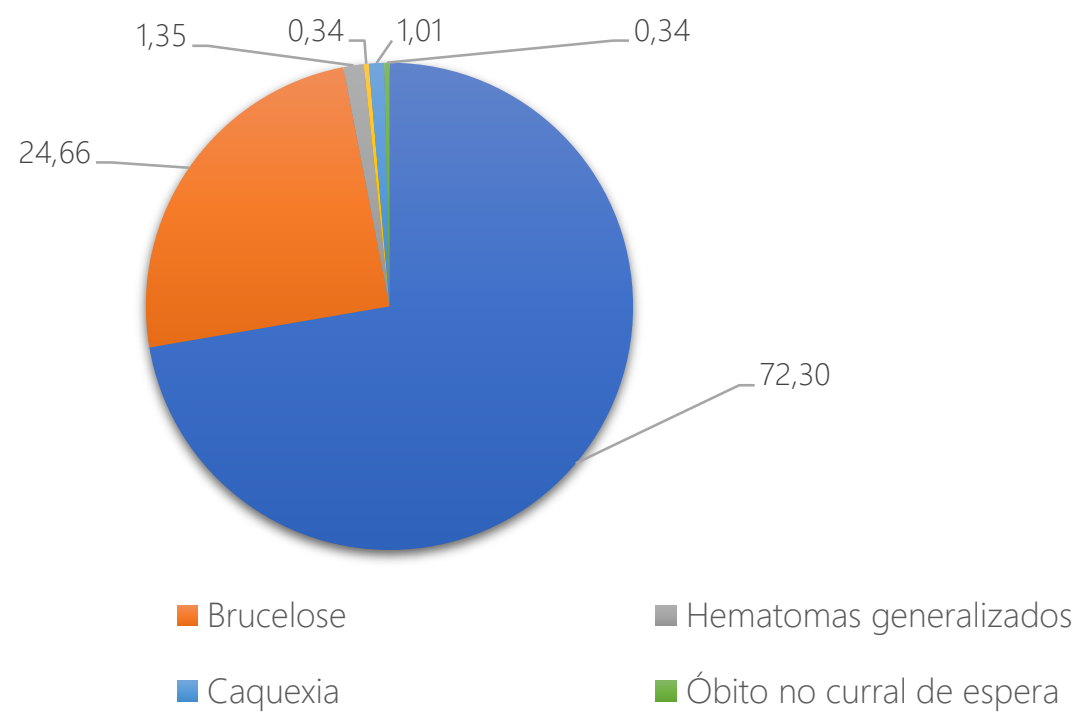

Fonte: SEMAP (2016), elaborado pelo autor.

Corroborando com os resultados da pesquisa, Araújo (2009) também verificou casos de condenações, principalmente, por tuberculose e brucelose, além de hematomas decorrentes de manejos pré-abate inadequados, em dois frigoríficos no município de Altamira (PA).

Dentre os casos registrados, as fêmeas apresentaram maior índice com 83,78\% ( $n=248)$ em comparação aos machos com 16,22\% ( $n=48)$ (Figura 2). 
Figura 2. Índices de condenações pela classe sexual.

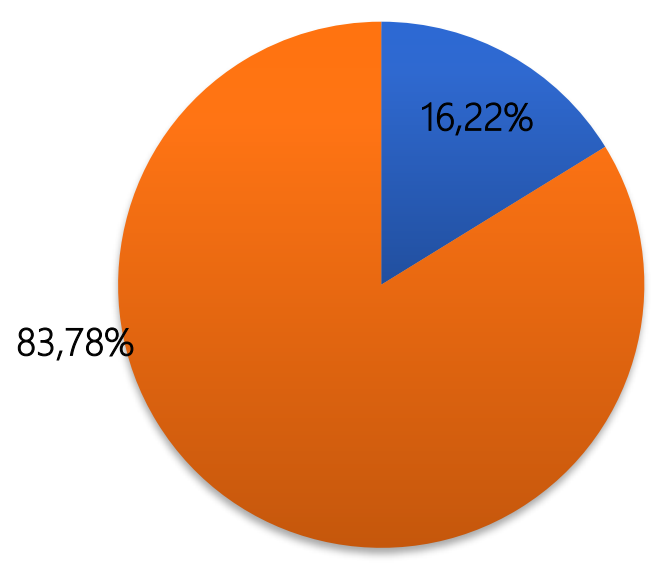

Machos Fêmeas

Fonte: SEMAP (2016), elaborado pelo autor.

Os 296 casos registrados pelo SIM perfizeram 0,57\% do volume abatido. Esse resultado está acima do obtido por Silva et al. (2016), que correspondeu 0,15\%, os quais realizaram um estudo sobre as principais causas de condenações em 64.793 carcaças de bovinos abatidos sob inspeção estadual no Paraná, utilizando metodologia semelhante.

As fêmeas tanto da espécie bovina quanto bubalina apresentaram os principais índices, respondendo, respectivamente, por $87,61 \%(n=198)$ e 71,43\% (n=50), em comparação aos machos das referidas espécies com $12,39 \%(n=28)$ e $28,57 \%(n=20)$ (Figura 3). 
Figura 3. Índices de condenações por classe sexual de acordo com a espécie.

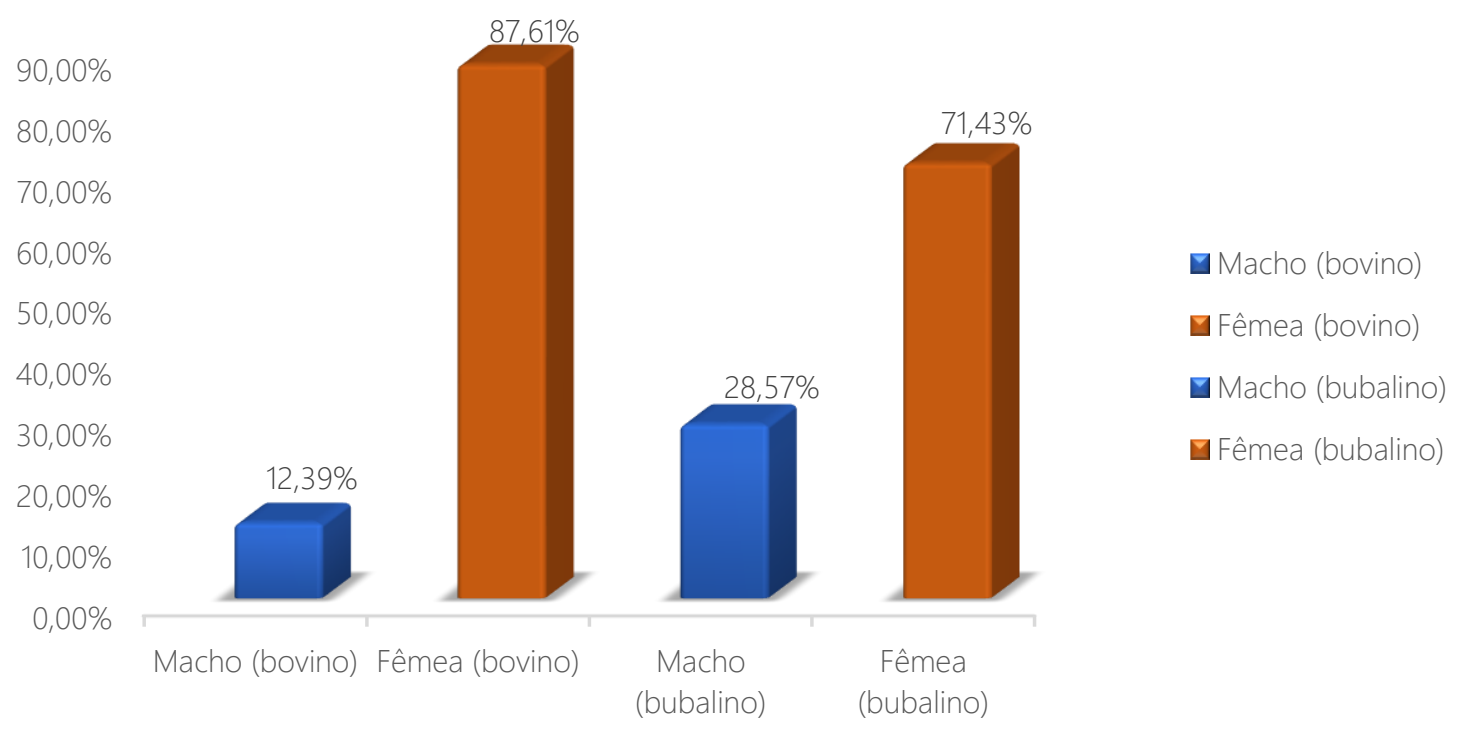

Fonte: SEMAP (2016), elaborado pelo autor.

Os resultados podem estar valorização excessiva de animais para relacionados com o fato de ter ocorrido engorda e, com isso, encarecendo o maior participação de fêmeas no produto final para o consumidor. Nesse período avaliado. Visando levantar contexto, alguns fatores influenciam para alguns dos principais pontos acerca do o aumento no abate de fêmeas, como a abate de fêmeas, Torres e Dreher (2015) reposição de matrizes no plantel e o alertam sobre o abate desenfreado de descarte de animais improdutivos, que vacas, que pode proporcionar correspondem às vacas que não futuramente redução no número de disponibilizaram bezerros após o bezerros, por haver tanto a redução dos período reprodutivo, depois do início da animais aptos para reprodução como estação das águas (CERVIERI, 2007; por manter maior número de animais jovens no rebanho, ocasionando SORNAS, 2014; CEPEA, 2017).

Dentre os animais condenados, dos 
quais 226 eram bovinos e 70 bubalinos, a espécie bovina apresentou registros, principalmente, por lesões sugestivas de tuberculose em 27 machos e 119 fêmeas, além de 73 casos por lesões de brucelose, enquanto que na bubalina, a principal causa de condenação foi por tuberculose em 48 fêmeas e 20 machos (Tabela 2).

Tabela 2. Distribuição das condenações pela classe sexual de acordo com a espécie.

\begin{tabular}{lccccc}
\hline \multirow{2}{*}{ Condenações } & No de & \multicolumn{2}{c}{ Bovinos } & \multicolumn{2}{c}{ Bubalinos } \\
\cline { 3 - 6 } & casos & Machos & Fêmeas & Machos & Fêmeas \\
\hline Tuberculose & 214 & 27 & 119 & 20 & 48 \\
Brucelose & 73 & - & 73 & - & - \\
Hematomas & 4 & - & 4 & - & - \\
Caquexia & 3 & 1 & 1 & - & 1 \\
Peritonite & 1 & - & & - & 1 \\
Óbito no curral & 1 & - & 1 & - & - \\
\hline Total & 296 & 28 & 198 & 20 & 50 \\
\hline
\end{tabular}

Fonte: SEMAP (2016), elaborado pelo autor.

Os resultados do presente estudo com relação às condenações por lesões de tuberculose estão acima do obtido por Silva et al. (2014), que no total de 38.172 bovinos abatidos em dois frigoríficos no nordeste paulistano, 100 animais apresentaram lesões características da doença. Porém, em búfalos, os resultados estão abaixo do observado por Freitas et al. (2001), que no total de 1.735 bubalinos abatidos, foram detectados 133 casos de alterações por essa zoonose. A baixa ocorrência na espécie bubalina, em especial aos machos, configura comportamento contrário ao estudo de Vale et al. (2013), que verificaram maior ocorrência de tuberculose em bubalinos que em bovinos.

Com relação à brucelose, segundo Silva et al. (2011), fêmeas bovinas estão entre as mais afetadas, fato este que pode ser confirmado na pesquisa, estando acima do obtido por Martinho 
et al. (2013), que após realizarem exames de 39.955 bovinos abatidos em um frigorífico municipal de Imperatriz (MA) verificaram 13 casos da doença. No tocante ao estudo, a não detecção da doença em búfalas reforça o relato de Fogast et al. (2002) que apontaram evidências de características distintas na cadeia epidemiológica da brucelose em bovinos e bubalinos, aumentando a necessidade de estudos específicos sobre a zoonose em bubalinos, visto que a maioria das pesquisas enfoca os bovinos.

As condenações por hematomas generalizados respeitaram o Art. 177 do Regulamento de Inspeção Industrial e Sanitária de Produtos de Origem Animal (RIISPOA) do Ministério da Agricultura, Pecuária e Abastecimento (MAPA) que rege a condenação de animais que apresentarem contusão generalizada. Ainda de acordo com a legislação, em casos de contusão localizada, o aproveitamento deve ser condicional (salga, salsicharia ou conserva) a juízo da inspeção, depois de removidas e condenadas as áreas atingidas (BRASIL, 1997).

Da mesma forma, os bovídeos que apresentarem sinais clínicos de caquexia, foram condenados conforme estabelece o RIISPOA no Art. 113, parágrafo 2. No relato de Alves (2011), devido sua enorme complexidade, a caquexia não é facilmente definida, e alguns autores a consideram como uma síndrome metabólica caracterizada por progressiva perda de peso.

Quanto ao caso de peritonite, Bassuino et al. (2016) considera essa doença muito comum em animais de produção, embora ser pouco conhecida pela maioria dos produtores, os quais devem ficar atentos aos primeiros sinais (sensibilidade abdominal) que podem trazer desconforto no animal. Outros sintomas podem ser apurados, como ascite (líquidos no abdômen), não evacuação de fezes ou gases, distensão abdominal, febre e vômitos (BASSUINO et al., 2016).

Por fim, a condenação por óbito no 
curral é um reflexo das principais consequências de manejos pré-abate inadequados, aos quais podem estar relacionadas às condições desfavoráveis de transporte, onde o animal é submetido a estresse constante, levando ao aparecimento de lesões na carcaça, perda de peso e consequentemente a morte (MELO et al., 2016).

\section{CONCLUSÃO}

O munícipio que apresentou maior ocorrência de condenações foi Santarém, atingindo mais da metade das condenações, sendo as fêmeas da espécie bovina predominante nas ocorrências por lesões sugestivas de tuberculose e brucelose, além de hematomas generalizados. Contudo, os resultados sinalizam que o município ainda necessita intensificar suas condições sanitárias e de manejo nas propriedades.

\section{REFERÊNCIAS}

ALVES, M. J. Efeito da caquexia associada ao câncer em componentes da matriz extracelular do tecido adiposo, São Paulo, 2011. 73 f. Dissertação (Mestrado em Ciências) - Universidade de São Paulo, Instituto de Ciências Biomédicas, Departamento de Biologia Celular e Tecidual, São Paulo, 2011.

ARAÚJJ, G. M. L. Principais causas de condenação de bovinos registradas pelos Serviços de Inspeção em frigoríficos do município de Altamira-PA, no período de Janeiro de 2007 a Dezembro de 2008, Altamira, 2009. 38 f. Trabalho de Conclusão de Curso (Graduação em Agronomia) Universidade Federal do Pará, Faculdade Federal do Pará, Altamira, 2009.

BASSUINO, D. M.; HAMMERSCHMITT, M. E.; KONRADT, G.; OLIVEIRA, L. S.; GONÇALVES, M. A.; SNEL, G. M.; DRIEMEIER, D.; PAVARINI, S. P. Surto de peritonite fibrinossupurativa por Trueperella pyogenes em bovinos, secundário à orquietomia. Revista Pesquisa Veterinária Brasileira, v. 36, p. 140-141, 2016.

BRASIL. Ministério da Agricultura, Pecuária e Abastecimento. Secretaria de Defesa Agropecuária. Departamento de Inspeção de Produtos de Origem Animal - DIPOA. Divisão de Normas Técnicas. Decreto Lei no 30.691, de 29 de março de 1952, alterado pelos Decretos $n^{\circ} 1.255$, de 25 de junho de 1962, n 1.236, de 2 de setembro de 1994, $n^{\circ} 1.812$, de 18 de fevereiro de 1996, e $n^{\circ} 2.244$ de 4 de junho de 1997. Regulamento de Inspeção 
Industrial e Sanitária de Produtos de Origem Animal. Brasília - DF. 1997. Disponível em: $<$ <ttp://www3.servicos.ms.gov.br/iagro_ ged/pdf/182_ged.pdf>. Acesso em: 18 set. 2017.

BRANDÃO, F. T.; JÚNIOR, J. C. F.; BRICH, L. O.; MIRANDA, I. T. P. Exportação da carne bovina nacional: os desafios que o setor enfrentará nos próximos anos frente às novas exigências do mercado internacional. Revista Maringá Management, v. 4, p.7-14, 2007.

CEPEA. Centro de Estudos Avançados em Economia Aplicada. BOI/CEPEA: Quedas nos preços do bezerro e do boi estimulam abate de fêmeas. 2017. Disponível em: < https://www.cepea.esalq.usp.br/br/docu mentos/texto/boi-cepea-quedas-nosprecos-do-bezerro-e-do-boiestimulam-abate-de-femeas.aspx>. Acesso em: 18 set. 2017.

CERVIERI, R. Engorda de novilhas prenhas e suas implicações sobre as características de carcaça. 2007. Disponível em: $<$ http://www.beefpoint.com.br/sistemas -deproducao/>. Acesso em 18 set. 2017.

CHAGAS, A. M.; FARIA, P. B.; COSTA, G. $M$. Prevalência de lesões sugestivas de brucelose em bovinos abatidos no Estado do Pará, Brasil. Revista PUBVET, v. 7, p. 2446-2564, 2013.

FOSGATE, G. T.; ADESIYUN, A. A.; HIRD,
D. W.; JOHNSON, W. O.; HIETALA, S. K.; SCHURIG, G. G. Comparison of serologic tests for detection of Brucella infections in cattle and water buffalo (Bubalus bubalis). American Journal of Veterinary Research, v. 63, p. 1598-1605, 2002.

FREITAS, J. A.; GUERRA, J. L.; PANETTA, J. C. Características da tuberculose observada em búfalos abatidos para consumo: aspectos patológicos e identificação de micobactérias. Brazilian Journal of Veterinary Research and Animal Science, v. 38, p. 170-176, 2001.

HOFFMANN, A.; MORAES, E. H. B. K.; MOUSQUER, C. J.; SIMIONI, T. A.; JUNIOR GOMES, F.; FERREIRA, V. B.; SILVA, H. M. Produção de bovinos de corte no sistema de pasto-suplemento no período seco. Revista Nativa, v. 2, p. 119-130, 2014.

MACHADO, G. B.; MOURA, S. V.; FORTES, T. P.; FACIN, D. V.; LANSINI, V.; SILVA, E. F. Principais causas de descarte em búfalos abatidos no estado do Rio Grande do Sul, Brasil. Science and Animal Health, v. 4, p. 56-66, 2016.

MARTINHO, F. S.; JUNIOR, F. G. S.; JUNIOR, S. S. D.; SANTOS, F. M.; GOMES, W. M. G.; CASTILHO, L. A. C. Diagnóstico de brucelose em bovinos no abatedouro municipal de Imperatriz - MA. Revista Agroecossistemas, v. 3, p. 41-44, 2013.

MELO, A. F.; MOREIRA, J. M.; ATAIÍDES, D. S.; GUIMARÃES, R. A. M.; LOIOLA, J. L.; OLIVEIRA, R. Q. Fatores 
que influenciam na qualidade da carne bovina: revisão. Revista PUBVET, v.10, p. 785-794, 2016.

OLIVEIRA, R. L.; BARBOSA, M. A. A. F.; LADEIRA, M. M.; SILVA, M. M. P.; ZIVIANI, A. C.; BAGALDO, A. R. Nutrição e manejo de bovinos de corte na fase de cria. Revista Brasileira de Saúde e Produção Animal, v. 7, p. 57-86, 2006.

REZENDE LAGO, N. C. M.; D'AMATO, C. C.; MARCHI, P. G. F. Perdas econômicas por abscessos e hematomas em carcaças de bovinos. Revista Eletrônica da Univar, v. 2, p. 154-157, 2011.

SANTOS, M. A. S.; CUNHA, S. J. T.; SANTOS, J. S. B.; SANTANA, A. C. Mercado e dinâmica local da cadeia produtiva da pecuária de corte na Região Norte. Belém: Banco da Amazônia, 2007, v. 1, 48 p.

SILVA, F. D. S.; SANTOS, N. A. F.; PACHECO, E. O.; LOPES, I. S.; PINHEIRO, M. F. N.; MAIA, M. P. Prevalência da brucelose bovina no estado do Maranhão, Brasil. In: CONGRESSO BRASILEIRO DE MEDICINA VETERINÁRIA, 38. Florianópolis. Anais...Florianópolis, 2011.

SILVA, D. A V.; BURGER, K. P.; MARTINS, A. M. C. V.; PROVIDELLO, A. Identificação de lesões macroscópicas sugestivas de tuberculose bovina. Revista Brasileira de Higiene e Sanidade Animal, v. 8, p. 149160, 2014.
SILVA, V. L.; GROFF, A. M.; BASSANI, C. A.; PIANHO, C. R. Causas de condenação total de carcaças bovinas em um frigorífico do estado do Paraná. Relato de caso. Revista Brasileira de Higiene e Sanidade Animal, Paraná, v. 10, p. 730741, 2016.

SORNAS, A. S. Impacto do abate de vacas prenhes sob parâmetros de carcaça e sua inflência no resultado econômico, Curitiba, 2014. 64 f. Trabalho de Conclusão de Curso (Graduação em Zootecnia) - Universidade Federal do Paraná, Curitiba, 2014.

TORRES, R. N. S.; DREHER, A. Uso de fêmeas (novilhas e vacas de descarte) para a produção de carne aspectos produtivos e qualidade. Revista Eletrônica Nutritime, v. 12, p. 4082-4089, 2015.

VALE, W. G.; MINERVINO, A. H. H.; NEVES, K. A. L.; MORINI, A. C.; COELHO, J. A. Buffalo under Threat in Amazon Valley, Brazil. Buffalo Bulletin, v. 32, p. $121-131,201$ 